\title{
Spatial aspects of reproduced sound in small rooms
}

\author{
Bech, Søren
}

Published in:

Acoustical Society of America. Journal

Link to article, DOI:

$10.1121 / 1.421098$

Publication date:

1998

Document Version

Publisher's PDF, also known as Version of record

Link back to DTU Orbit

Citation (APA):

Bech, S. (1998). Spatial aspects of reproduced sound in small rooms. Acoustical Society of America. Journal, 103(1), 434-445. https://doi.org/10.1121/1.421098

\section{General rights}

Copyright and moral rights for the publications made accessible in the public portal are retained by the authors and/or other copyright owners and it is a condition of accessing publications that users recognise and abide by the legal requirements associated with these rights.

- Users may download and print one copy of any publication from the public portal for the purpose of private study or research.

- You may not further distribute the material or use it for any profit-making activity or commercial gain

- You may freely distribute the URL identifying the publication in the public portal

If you believe that this document breaches copyright please contact us providing details, and we will remove access to the work immediately and investigate your claim 


\title{
Spatial aspects of reproduced sound in small rooms
}

\author{
Søren Bech ${ }^{\text {a) }}$ \\ Department of Acoustic Technology, Technical University of Denmark, DK-2800 Lyngby, Denmark
}

(Received 9 April 1996; accepted for publication 8 October 1997)

This paper reports on the influence of individual reflections on the auditory spatial aspects of reproduced sound. The sound field produced by a single loudspeaker positioned in a normal listening room has been simulated using an electroacoustical synthesis of the direct sound, 17 individual reflections and the reverberant field. The threshold of detection was measured using the method of adjustment for five reflections using three subjects for noise and speech. The thresholds have been measured for two simulated situations (1) a loudspeaker with a frequency independent directivity characteristics and frequency independent absorption coefficients of the room surfaces and (2) a loudspeaker with directivity similar to a standard two-way system and absorption coefficients according to measurements of real materials. The results have shown that subjects can reliably distinguish between timbre and spatial aspect of the sound field, that the spectral energy above $2 \mathrm{kHz}$ of the individual reflection determines the importance of the reflection for the spatial aspects, and that only the first order floor reflection will contribute to the spatial aspects. (C) 1998 Acoustical Society of America. [S0001-4966(98)05701-4]

PACS numbers: 43.55.Hy, 43.55.Jz, 43.55.Lb, 43.66.Qp [JDQ]

\section{INTRODUCTION}

This is a report on the third experimental investigation of perception of reproduced sound in small rooms. The first two investigations $\left(\mathrm{Bech}^{1}\right.$ referenced below as Paper I and $\mathrm{Bech}^{2}$ referenced as Paper II) were concerned with the influence of individual reflections on the timbre of the sound field produced by a single loudspeaker positioned in a room the size of a normal living room. This report is concerned with the influence of individual reflections on the spatial aspects of reproduced sound.

The overall purpose of the experiments reported in $\mathrm{Pa}$ pers I and II and the present is to examine the importance of individual early reflections on the perceived sound quality. The results might form the basis for development of new loudspeaker systems which in some way can accommodate the acoustics of the room in which they are placed. Therefore, the experiments have been designed to illuminate questions of relevance for the design of such new loudspeaker systems. In this report the following question has been addressed:

Which of the early reflections are sufficiently strong to contribute individually to the auditory spatial aspects of reproduced sound, and which only contribute collectively?

This question is primarily related to the design of the directivity characteristics of the loudspeaker.

To facilitate the investigations, the sound field from a single loudspeaker in a listening room has been simulated using an electroacoustic setup. Two situations have been simulated using the same room dimensions and positions of the listener and loudspeaker.

One simulates the sound field from an idealized loudspeaker with a frequency-independent cardioid directivity, positioned in a room where the surfaces have idealized

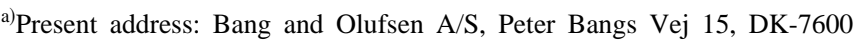
Struer, Denmark.
}

frequency-independent absorption characteristics. This situation is termed "unfiltered" in the following.

The other, termed filtered, simulates the sound field from a loudspeaker with directivity characteristics like a standard two-way loudspeaker system, positioned in a room where the surfaces have realistic absorption characteristics.

The results from the unfiltered situation provide a link with previous research in this area, which almost exclusively has been based on conditions similar to the unfiltered situation. Furthermore, the unfiltered situation is better suited to examine the importance of different regions in the spectrum of the reflections.

The filtered situation is expected to provide results which are more in agreement with the conditions in a real room. By comparing results from the unfiltered and filtered situations it is expected to provide further information on the relative importance of different frequency regions.

\section{EXPERIMENTAL SETUP}

The sound field produced by the right hand loudspeaker of a stereophonic setup positioned in a domestic listening room was electroacoustically simulated. The listening room which has formed the basis for the simulation was built in accordance with the IEC $268-13^{3}$ recommendation, whereby the room should be representative of a domestic listening room.

Two different versions of the sound field have been used for the investigations. The first, the "unfiltered" version modeled the directivity characteristics of the loudspeaker as a cardioid, independent of frequency. The absorption coefficients of the room surfaces were also modeled as being independent of frequency.

The "filtered" version was modeled as a two-way loudspeaker system with directivity characteristics according to the measurements of a selected loudspeaker (KEF 103.2). 
TABLE I. Positions of loudspeakers and delay and attenuation of the signals to the loudspeakers for primary loudspeaker, images and reverberation channels included in the setup. The attenuation values are given for the unfiltered situation (Att. I) and the filtered situation (Att. II). The last wall of the reflection path is also given. All angles and wall references are relative to the listening position and the left-hand side of the subject defines positive angles.

\begin{tabular}{|c|c|c|c|c|c|c|}
\hline $\begin{array}{l}\text { Delay } \\
{[\mathrm{ms}]}\end{array}$ & $\begin{array}{l}\text { Att. I } \\
{[\mathrm{dB}]}\end{array}$ & $\begin{array}{c}\text { Att. II } \\
{[\mathrm{dB}]}\end{array}$ & $\begin{array}{l}\text { Azimuth } \\
\text { [degrees] }\end{array}$ & $\begin{array}{l}\text { Elevation } \\
\text { [degrees] }\end{array}$ & $\begin{array}{c}\text { Reflection } \\
\text { number }\end{array}$ & $\begin{array}{l}\text { Last surface } \\
\text { of reflection }\end{array}$ \\
\hline 0 & 0 & 0 & -22 & 0 & $\ldots$ & primary lsp \\
\hline 1.64 & 3.6 & 1.36 & -25 & -28 & 1 & floor \\
\hline 4.16 & 9.2 & 3.1 & -50 & -2 & 2 & right wall \\
\hline 4.48 & 5 & 3.28 & -25 & 48.2 & 3 & ceiling \\
\hline 5.36 & 11.6 & 3.81 & -53 & -28 & 4 & floor \\
\hline 7.6 & 11.8 & 5.01 & -50 & 48 & 5 & ceiling \\
\hline 9.2 & 10 & 5.78 & -25 & 48.2 & 6 & ceiling \\
\hline 9.2 & 10 & 5.78 & -25 & -56 & 7 & floor \\
\hline 9.94 & 9.7 & 6.11 & 65 & 0 & 8 & left wall \\
\hline 10.8 & 11.8 & 6.48 & 65 & -14 & 9 & left wall \\
\hline 11.64 & 15.5 & 6.83 & -53 & -56 & 10 & floor \\
\hline 11.64 & 15.5 & 6.83 & -50 & 48 & 11 & ceiling \\
\hline 12.5 & 11.5 & 7.17 & 65 & 30 & 12 & left wall \\
\hline 12.7 & 9.9 & 7.25 & -170 & 0 & 13 & backwall \\
\hline 13.46 & 11.9 & 7.54 & -170 & -15 & 14 & back wall \\
\hline 14.42 & 14.3 & 7.9 & -25 & -56 & 15 & floor \\
\hline 14.8 & 14.6 & 8.03 & -154 & 0 & 16 & back wall \\
\hline 14.98 & 11.3 & 8.09 & -170 & 33 & 17 & back wall \\
\hline 22 & 0.5 & 6 & 71 & 0 & $\ldots$ & rev. syst. \\
\hline 22 & 0.5 & 6 & -71 & 0 & $\cdots$ & rev. syst. \\
\hline 22 & 7.5 & 6 & 127 & 0 & $\ldots$ & rev. syst. \\
\hline 22 & 7.5 & 6 & -127 & 0 & $\cdots$ & rev. syst. \\
\hline 22 & 8.5 & 6 & 180 & 0 & $\cdots$ & rev. syst. \\
\hline 22 & 0.5 & 6 & 0 & 0 & $\ldots$ & rev. syst. \\
\hline
\end{tabular}

The absorption coefficients of the room surfaces were modeled as a function of frequency.

The electroacoustic setup models the direct sound, 17 individual reflections arriving less than $22 \mathrm{~ms}$ after the arrival of the direct sound, and the reverberant part of the sound field or reflections arriving more than $22 \mathrm{~ms}$ after the arrival of the direct sound. The setup was positioned in the large $\left(1000 \mathrm{~m}^{3}\right)$ anechoic chamber of the Department of Acoustic Technology, and all loudspeakers were located, with correct azimuth and elevation, on the surface of an imaginary sphere of 3-m radius centered at the listening position. The positions of all the loudspeakers, and the delay and attenuation of all signals representing individual images and reverberation channels, are given in Table I. In the following, individual reflections will be identified either by the delay relative to the direct sound, or by the number given in Table I. General considerations on electroacoustical simulation of sound fields are given in Paper I and a detailed discussion of the setup used for the present experiments is given in Paper II.

\section{A. Implementation of the direct sound and individual reflections for the unfiltered situation}

The directivity characteristics of the loudspeaker were modeled as a cardioid, independent of frequency. The absorption coefficients of the room surfaces were modeled independent of frequency with the following values: ceiling $=0.05$, floor $=0.3$, and walls $=0.44$. These values resulted in a calculated reverberation time of $0.4 \mathrm{~s}$, independent of frequency.
Delay and attenuation due to path lengths of the direct sound and individual reflections were calculated using the image source theory, implemented as a computer program by KEF Audio Ltd. The calculated levels of the individual reflections are hereafter referred to as the natural levels, as they represent the levels that the reflections would have in a real room with the specified properties.

For a general discussion of the image source principle, see, e.g., Cremer and Müller ${ }^{4}$ and Berman ${ }^{5}$ for use in a rectangular room.

\section{B. Implementation of the direct sound and individual reflections for the filtered situation}

The modeled loudspeaker was a two-way system (KEF 103.2) with an 8-in. woofer and a 1-in. tweeter, and a crossover frequency of $2.5 \mathrm{kHz}$. They were mounted in a closed box of dimensions $\left(\mathrm{w}^{*} \mathrm{~h}^{*} \mathrm{~d}^{*}\right) 264 * 501 * 240 \mathrm{~mm}$. The freefield frequency response of the loudspeaker was measured in directions corresponding to the position of the images given in Table I at a distance of $3 \mathrm{~m}$, with the fabric grille removed. The geometrical center of the baffle was defined as the center of the loudspeaker.

The frequency-dependent absorption of the room surfaces was modeled according to measurements of the diffuse field absorption coefficient and the cosine law (see, e.g., Cremer \& Müller $\left.{ }^{4}\right)$ in the following way:

The absorption material used on the walls in the modeled listening room was distributed in such a way that the same mean absorption coefficient could be used for all four 
TABLE II. Diffuse field absorption coefficients for the various room surfaces as a function of one-third octave frequencies.

\begin{tabular}{cccc}
\hline \hline $\begin{array}{c}\text { One-third oct. } \\
\text { frequency [Hz] }\end{array}$ & $\begin{array}{c}\text { Absorption } \\
\text { coefficient } \\
\text { for walls }\end{array}$ & $\begin{array}{c}\text { Absorption } \\
\text { coefficient } \\
\text { for floor }\end{array}$ & $\begin{array}{c}\text { Absorption } \\
\text { coefficient } \\
\text { for ceiling }\end{array}$ \\
\hline 50 & 0.05 & 0.05 & 0.15 \\
63 & 0.17 & 0.06 & 0.13 \\
80 & 0.28 & 0.07 & 0.11 \\
100 & 0.45 & 0.08 & 0.1 \\
125 & 0.46 & 0.09 & 0.09 \\
160 & 0.35 & 0.1 & 0.08 \\
200 & 0.34 & 0.12 & 0.08 \\
250 & 0.41 & 0.14 & 0.07 \\
315 & 0.37 & 0.16 & 0.07 \\
400 & 0.4 & 0.19 & 0.07 \\
500 & 0.41 & 0.24 & 0.06 \\
630 & 0.33 & 0.28 & 0.06 \\
800 & 0.25 & 0.33 & 0.06 \\
1,000 & 0.24 & 0.35 & 0.05 \\
1,250 & 0.31 & 0.33 & 0.05 \\
1,600 & 0.15 & 0.31 & 0.05 \\
2,000 & 0.16 & 0.28 & 0.04 \\
2,500 & 0.18 & 0.25 & 0.04 \\
3,150 & 0.16 & 0.22 & 0.04 \\
4,000 & 0.14 & 0.2 & 0.03 \\
5,000 & 0.18 & 0.18 & 0.03 \\
6,300 & 0.18 & & \\
8,000 & 0.19 & & 0.16 \\
\hline \hline
\end{tabular}

walls, and was estimated using diffuse field measurements of the individual components. The absorption coefficients for the floor and the ceiling were also based on diffuse field measurements.

The absorption coefficients for the walls, the floor, and the ceiling are given in Table II. The absorption coefficient as a function of angle was found by setting the diffuse field coefficient equal to the absorption at an angle-of-incidence of 45 degrees, and then applying the cosine law for other angles. Rindel ${ }^{6}$ discusses the derivation of an angledependent absorption coefficient based on diffuse field measurements ${ }^{7}$

The frequency responses of the signal paths for individual loudspeakers in the simulation setup were calculated taking into account the directivity characteristics and absorption coefficients as discussed above, and were implemented as digital filters. The digital signal processing system has been described by Fincham and Small, ${ }^{8}$ Brookes et al. ${ }^{9}$ and Christensen. ${ }^{10}$

The implemented transfer function for selected reflections are shown in Fig. 1. Note that the transfer functions have been adjusted to include the attenuation due to distance, as given in Table I.

\section{Implementation of the reverberant field}

The reverberant field was created by six loudspeakers positioned in the equatorial plane of the imaginary sphere described above. Signals for the six loudspeakers were based on the outputs from three commercially available reverberation units (Lexicon PCM 70). Each unit produces two uncorrelated outputs and the settings of the units were slightly different, so that a total of six uncorrelated signals were produced. A block diagram of the complete setup is shown in Fig. 2.

The level of the reverberant field, relative to the level of the direct sound and individual early reflections was calculated for the unfiltered situation, assuming a reverberation time of $0.4 \mathrm{~s}$ at $1 \mathrm{kHz}$, and an exponential decay.

For the filtered situation, the ratio was adjusted to be equal to the ratio measured in the real room at $1 \mathrm{kHz}$. The ratio as a function of frequency is shown in Table III for the setup and the real room.

\section{Subject positioning and calibration procedures}

The listener's ears were moved to the specified listening position using a motorized adjustment mechanism built into the chair supporting the subject, and a fixed video camera. A curtain prevented the listener from seeing the simulation setup, while a single LED was used to define the front angular reference. Listeners were free to move their heads, but were instructed to focus their attention on the LED. The performance and calibration of the entire setup was checked on a daily basis using a PC-controlled measuring system. For further details see Paper I.

\section{STIMULI}

The signals used were continuous broadband $(20 \mathrm{~Hz}-20$ $\mathrm{kHz}$ ) pink noise, and a repeated 1.45 -min segment of continuous male speech. The spoken text was a recording of an excerpt of the text used for the standardized Danish speech material for audiometric purposes, made in the large anechoic chamber of the Department of Acoustic Technology. The time structure and spectrum of the chosen speech sample are representative of average Danish speech. High and low pass filtered ( $24 \mathrm{~dB} /$ octave) pink noise, with crossover frequencies at $500 \mathrm{~Hz}$ and $2 \mathrm{kHz}$, respectively, were used for the experiments reported in Sec. V A 3.

For a further description of the speech recordings see Hansen and Munch ${ }^{11}$ or the CD cover (Bang and Olufsen CD 101, track 9). The signals were turned off and on using $1.5 \mathrm{~s}$ cosine-squared ramps.

The reproduction level was $60 \mathrm{~dB}$ SPL for the noise stimuli and approximately $50 \mathrm{~dB}$ SPL (time weighting Fast) for the speech. The level of the speech stimulus was set to correspond to normal conversational level at 3-m distance in a living room. The background noise level with the simulation system switched on was $27 \mathrm{~dB}$ SPL (time weighting Fast). The one-third octave band level of the background noise is constant $\pm 2 \mathrm{~dB}$ for the frequency range $20 \mathrm{~Hz}-20$ $\mathrm{kHz}$.

\section{SUBJECTS}

Three subjects participated in the experiments. They had all participated in the experiments reported in Papers I and II and must therefore be considered highly trained subjects. They furthermore participated in training experiments before the main experiments. The subjects were paid an hourly rate for their services. 

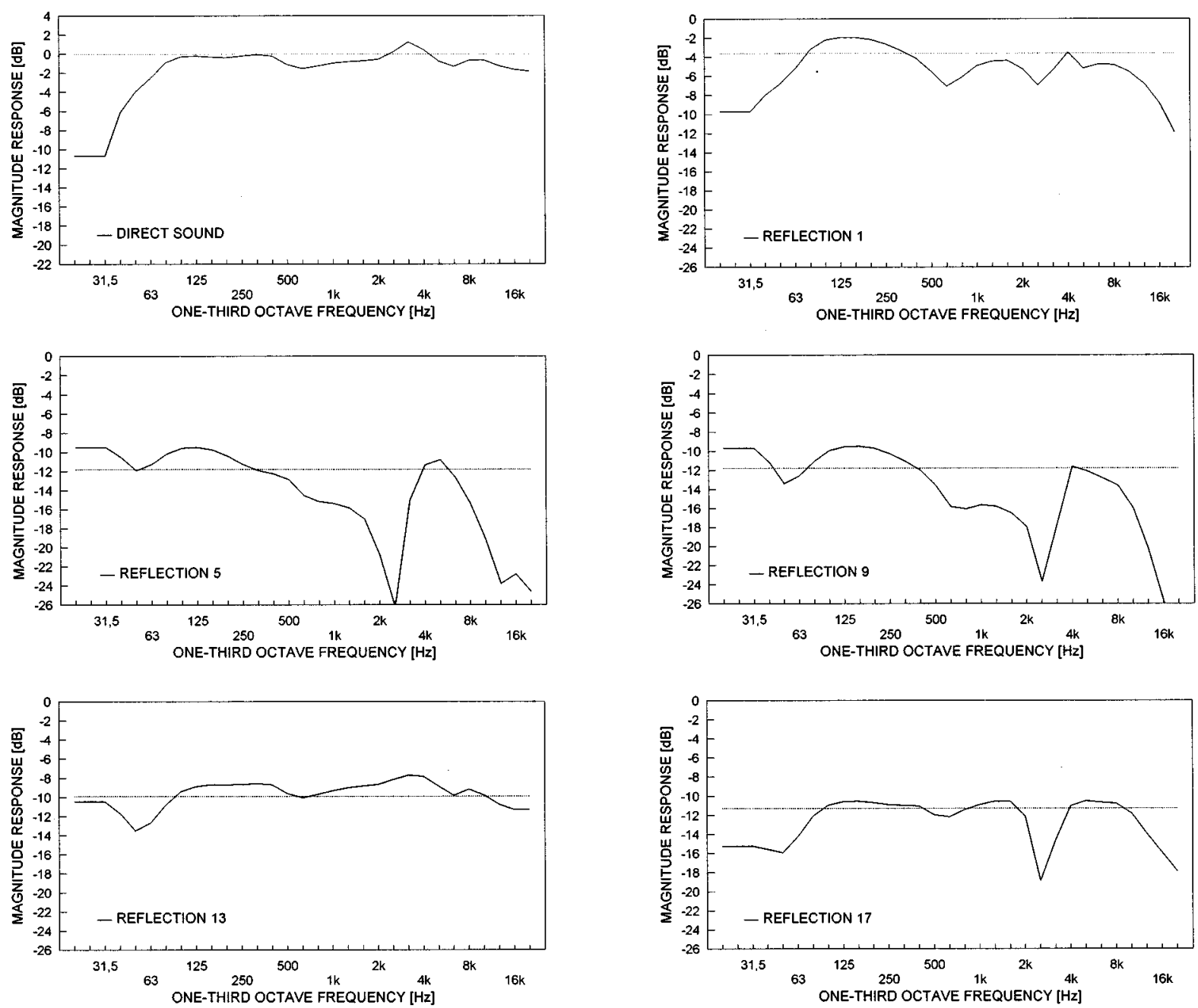

FIG. 1. Magnitude response of the filter functions implemented for the direct sound and individual reflections for the filtered situation. The dashed line represents the frequency-independent attenuation used for the unfiltered situation. Note that transfer functions are only given for the investigated reflections. The reflection number refers to Table I.

\section{GENERAL PROCEDURE}

\section{A. Subject's task}

The purpose of the experiments was to establish threshold values for changes in the auditory spatial aspects of reproduced sound. In contrast to the timbral thresholds discussed in Papers I and II, the spatial aspects could include a number of different attributes that all could be potential candidates for a definition of a threshold.

Haas, ${ }^{12}$ Meyer and Schodder, ${ }^{13}$ Lochner and Burger, ${ }^{14}$ and Olive and Toole ${ }^{15}$ have all investigated the spatial effects of combining a direct sound with a single reflection. They have reported a number of spatial attributes, depending on the signal, the time delay, and level of the reflection, that are all potential cues for a threshold definition.

Haas, ${ }^{12}$ for the same level of the direct sound and the reflection, noted changes in the position of the virtual sound source ( $0-1 \mathrm{~ms}$ delay of the reflection), an increase in "liveliness," "body," spaciousness ("pseudostereophonic" effect) of the sound, and an increase in the overall loudness (0-30 ms).

Meyer and Schodder ${ }^{13}$ found an increase in the apparent size of the direct sound source and the spaciousness of the overall sound for a situation where the direct sound and the reflections were equally loud.

Lochner and Burger ${ }^{14}$ note that the effects of the reflection was distinctly noticeable long before it was perceived as a separate sound source (0-10 ms delay).

Olive and Toole ${ }^{15}$ note an image shift or spreading (delay less than $10 \mathrm{~ms}$ ), spaciousness and image spreading $(10-40 \mathrm{~ms})$ for levels of the reflection well above the absolute threshold which corresponds to a detection of any audible changes.

Toole ${ }^{16}$ has an excellent review of the different spatial effects discussed above. The experience thus indicates that great care should be taken in defining the auditory cue when measuring spatial aspects of reproduced sound. The literature reviewed above suggests three distinctly different thresholds based on (1) equal loudness of the direct sound and the reflection as used by Haas, ${ }^{12}$ Meyer and Schodder, ${ }^{13}$ and Lochner and Burger, ${ }^{14}(2)$ the reflection can be identified as a separate sound source as used by Meyer and Schodder ${ }^{13}$ and Lochner and Burger, ${ }^{14}$ and (3) a just discernible shift in the 


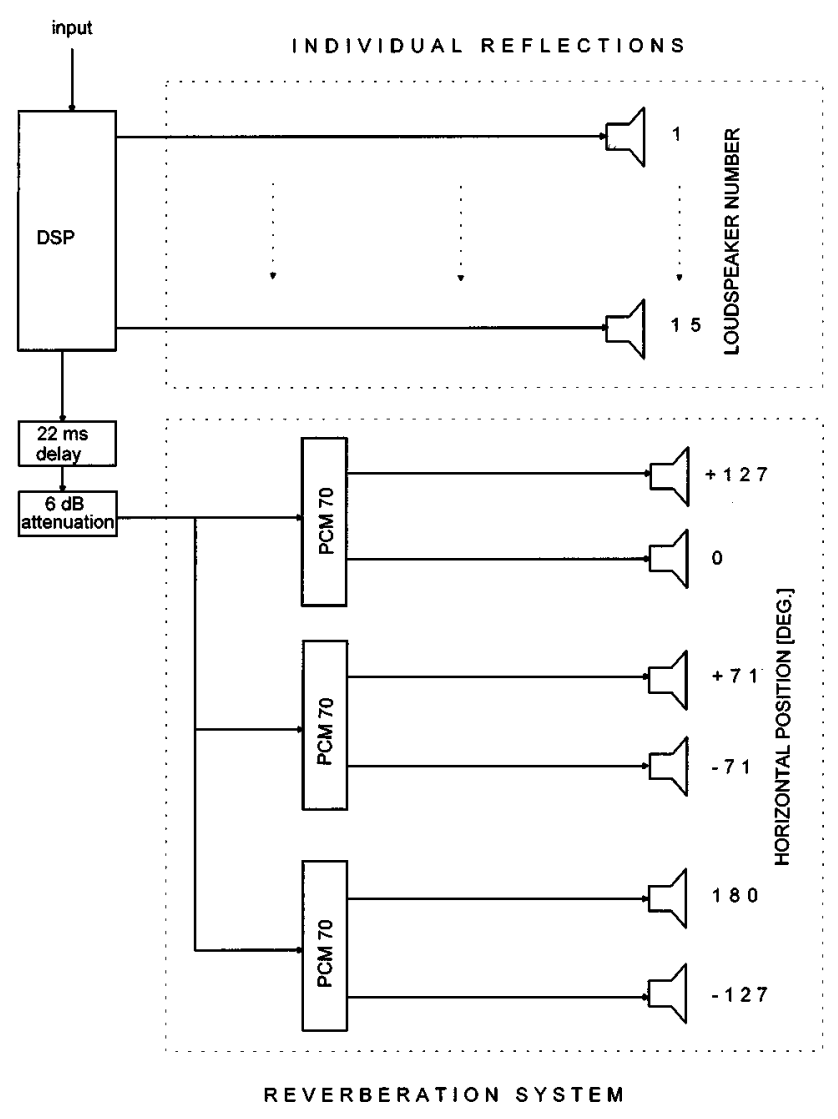

FIG. 2. Block diagram of the complete experimental setup. The DSP unit implemented the transfer functions shown in Fig. 1 and the delay and attenuation due to distance, here shown separately for sake of clarity. Note that the reflection loudspeakers can represent more than one image, cf. Table I and that 0 degrees corresponds to the front angular reference for the subject and positive angles are to the left-hand side.

location or size of the principal auditory image as used by Olive and Toole. ${ }^{15}$

The threshold values corresponding to the definitions (1) -(3) are each separated by approximately $10 \mathrm{~dB}$ in level of the reflection and definition 3 leads, according to Olive and Toole, ${ }^{15}$ to the lowest threshold approximately $7 \mathrm{~dB}$ above the absolute threshold based on timbre. The threshold definitions according to (2) and (3) were thus judged to be the most relevant for the present series of experiments and the subjects were instructed to base their detection on either the appearance of a second and separate sound source or a change in perceived size or position of the principal sound

TABLE III. The level of the direct sound and the early reflections relative to the level of the diffuse part of the sound field as measured in the real room and in the simulation setup.

\begin{tabular}{ccc}
\hline \hline $\begin{array}{c}\text { One octave } \\
\text { frequency }[\mathrm{Hz}]\end{array}$ & $\begin{array}{c}\text { Ratio for } \\
\text { real room }[\mathrm{dB}]\end{array}$ & $\begin{array}{c}\text { Ration for } \\
\text { simulation }[\mathrm{dB}]\end{array}$ \\
\hline 125 & -0.8 & 2.2 \\
250 & 0.4 & 5 \\
500 & 4.6 & 5.2 \\
1000 & 5.3 & 5.3 \\
2000 & 6.4 & 5.4 \\
4000 & 4.4 & 9.1 \\
8000 & 6.5 & 11.7 \\
\hline \hline
\end{tabular}

source. A pilot experiment was conducted to gain more experience and the results showed quite clearly that the only well defined spatial cue was based on the appearance of a second sound source. By a secondary sound source it is meant that, in addition to the principal sound source, a second source with a distinct spatial position different from the principal source appeared in the sound field. The subjects all agreed on the existence of this cue and its definition. The subjects were thus instructed to use this cue for the main experiments.

Note that in the following part of the paper the threshold related to the appearance of a second sound source will be referred to as the threshold for spatial aspects of the sound field. This is justified by the existence of only three distinctly different thresholds in the simulated sound field: timbre, appearance of a second sound source, and loudness. Of these only one was related to changes in the spatial aspects of the sound field.

\section{B. Method}

The threshold of detection of the reflection under investigation was determined using the method of adjustment procedure. The subject could switch between the standard and a comparison sound field by means of two push buttons at any time during the experiment.

The standard and the comparison stimuli are defined as follows:

The standard is the complete sound field simulating a single loudspeaker in the listening room, except that the reflection under investigation is missing $(-50 \mathrm{~dB} r e$ : direct sound). The comparison stimulus is formed by adding, at a variable level, the reflection under investigation to the standard sound field.

The level of the reflection was controlled by the subject by two other push buttons; one would increase the level and the other decrease the level in steps of $0.5 \mathrm{~dB}$. A fifth push button allowed the subject at any time to switch to the initial comparison field with the reflection at it's initial level. This feature allowed the subject to "refresh" the initial character of the change in the sound field. Note that the sound was switched on and allowed to reach the maximum reproduction level before the subject could start to adjust the level of the reflection.

The subjects were instructed to stop the experiment with the reflection at a level where they could just discriminate between the standard and the comparison stimulus, and such that a 1 step reduction in level (equal to $0.5 \mathrm{~dB}$ ) caused the difference to disappear.

The chosen step size was a compromise between resolution of the procedure and ease of use, as a smaller step size caused difficulties for the subjects at the threshold. They found it difficult to adjust the level such that one step down caused the difference to disappear.

The initial level of the reflection was set to either $0 \mathrm{~dB}$ or $+5 \mathrm{~dB}$ re the direct sound, depending on the experiment. This ensured that there was a definite difference between the standard and the comparison stimulus.

Each subject participated in eight experiments as shown in Table IV and in each experiment threshold values were 
TABLE IV. Experimental conditions examined in the paper. The abbreviation HP500 means high-pass filtered with cross-over frequency at $500 \mathrm{~Hz}$ and LP2k means low-pass filtered with cross-over frequency at $2 \mathrm{kHz}$.

\begin{tabular}{|c|c|c|c|c|}
\hline Exp. number & Attribute & Stimulus & Filtering & Results in Fig. \\
\hline 1 & spatial aspects & noise & no & $3,4,5$ \\
\hline 2 & spatial aspects & noise & no & 4 \\
\hline 3 & spatial aspects & $\begin{array}{l}\mathrm{HP}, 500 \mathrm{~Hz} \\
\text { noise } \\
\mathrm{LP}, 500 \mathrm{~Hz}\end{array}$ & no & 4 \\
\hline 4 & spatial aspects & $\begin{array}{c}\text { noise } \\
\mathrm{HP}, 2 \mathrm{kHz}\end{array}$ & no & 4 \\
\hline 5 & spatial aspects & $\begin{array}{c}\text { noise } \\
\mathrm{LP}, 2 \mathrm{kHz}\end{array}$ & no & 4 \\
\hline 6 & timbre & noise & no & 3,8 \\
\hline 7 & spatial aspects & noise & yes & 5,6 \\
\hline 8 & spatial aspects & speech & yes & 6,7 \\
\hline
\end{tabular}

measured for five reflections (nos. 1, 5, 9, 13, and 17). The individual thresholds are defined as the mean of four repetitions and the reported threshold is the mean across subjects. The mean threshold is reported relative to the level of the direct sound.

The subject's participation was organized so that two subjects participated at the same time. While one subject was running one block of four repetitions, that is measuring the threshold for one reflection, the other subject was resting. The four repetitions were separated by small breaks of $2-5$ min. while the subject remained in the setup and rested. One block lasted approximately $15 \mathrm{~min}$. After completing one block the two subjects interchanged and the other subject ran a block. A pair of subjects would work for approximately two hours equal to running five blocks each, before they had a break of 2-4 h. No subject would participate in more than two such $2 \mathrm{~h}$ sessions per day.

Threshold values have only been measured for reflections $1,5,9,13$, and 17 in the experiments. The limitations in number of reflections was caused by time constraints, and the selection of reflections was based on a wish to be able to compare results with those of timbre, reported in Paper II.

\section{Discussion of experimental method}

When the level of the reflection was set to its initial level there was a definite perceived difference between the standard and the comparison stimulus. The difference consisted of a loudness difference, the appearance of a second sound source, and a timbral difference. A decrease in the reflection level caused the loudness difference to disappear, and a further decrease caused the differences related to the second source to disappear. The difference in timbre was the last to disappear, which means that the threshold of interest in the present series of experiments was reached while the timbral differences still existed. This means that the chosen experimental method should allow the subjects to discriminate between two coexisting cues. This proved difficult when the adaptive two alternative forced choice method as employed in Papers I and II was used. Another method was thus needed and as other researchers in this area (Haas, ${ }^{12}$ Seraphim,,${ }^{17}$ and Olive and Toole ${ }^{15}$ ) had used the method of adjustment (MOA) it was decided to examine this method further.
Cardozo ${ }^{18}$ noted that one of the principal applications of the MOA is in cases where the stimuli differ for one or more attributes at the same time. It is well known (Cardozo, ${ }^{18}$ Wier et al. ${ }^{19}$ and $\mathrm{Hesse}^{20}$ ), however, that results obtained with adjustment procedures, where the subject actively changes the stimuli under test, are different from those obtained with forced choice procedures, where the subjects have to choose one of two or more alternative presentations. The main criticism of the MOA is caused by the fact that the influence of variables like the step size, the number of stimuli presentations used for the evaluation, and the subjects' strategy for termination cannot be quantified like they can for the forced choice procedures. The MOA procedure, however, has been shown $\left(\right.$ Cardozo, ${ }^{18} \mathrm{Hesse}^{20}$ ) to possess a number of advantages compared to forced choice procedures. These include the ability to focus on a specific attribute of several possibilities, that the subject can optimize the stimulus presentation to suit his needs, that it has a significantly higher efficiency, and that the intra-individual reproducibility is higher.

The advantages of the MOA procedure, as discussed above, were found to outweigh the disadvantages in the present situation and it was decided to test the method in a series of training experiments. The results showed that the subjects were quite comfortable with the method and that they had no problems in separating the two auditory cues. It was thus decided to use the method in the main experiments.

However, to be able to link the current set of results to those reported in Papers I and II it was decided to measure the differences between timbral thresholds obtained with the MOA and 2AFC procedures. It was thus implicitly assumed that similar differences would be found for spatial aspects. The results are further discussed in Sec. VI C.

\section{RESULTS}

\section{A. Results for the unfiltered situation}

The purpose of these experiments (Nos. 1-6 in Table IV) was to measure the threshold of detection (TD) for individual reflections for different conditions, and to compare the TD values with the natural level of the reflection as calculated by an image model. However, the basic assumption that the subject can discriminate between a change in the spatial aspects of the reproduced sound and a timbral change, will first be examined.

\section{Discrimination between thresholds for timbre and spatial aspects}

The experiments are based on the assumption that subjects can discriminate between a change in spatial aspects and timbre of the sound field. The timbral threshold is assumed to represent the lowest threshold and changes in spatial aspects are found for higher levels of the reflection. Below the lowest threshold there are no subjective differences at all between the two sound fields.

The threshold of detection for the two tasks were measured and are shown in Fig. 3. The results show that the TD values for timbre are always lower than the TD's for spatial 


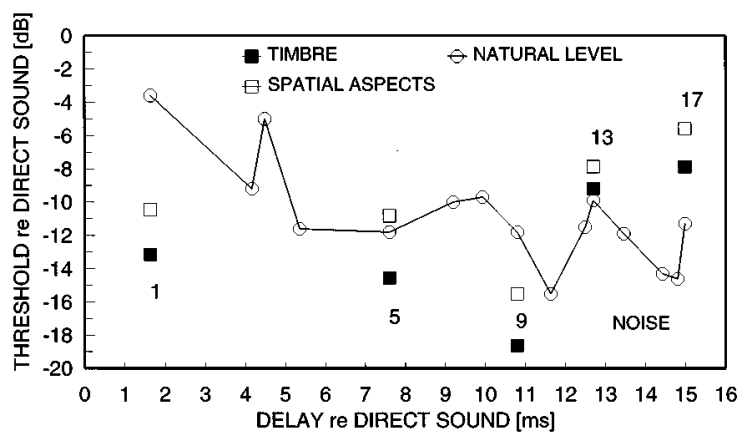

FIG. 3. Mean threshold values for a change in spatial aspects and in timbre for the unfiltered situation and the noise signal. The mean values are based on three subjects and four repetitions for each subject. Confidence intervals $(95 \%)$ based on the within-subject variance are $\pm 1.2 \mathrm{~dB}$ (spatial) and $\pm 1.8 \mathrm{~dB}$ (timbre). The natural levels of the individual reflections based on an image model are also shown as are the individual reflection numbers according to Table I.

aspects. This is in agreement with the reports of the subjects, who claimed that they always could hear a timbre difference when they reached the spatial threshold.

The differences observed in Fig. 3 between the timbral and spatial thresholds are approximately $3 \mathrm{~dB}$ for reflections $1,5,9$, and 17 and $1.5 \mathrm{~dB}$ for reflection 13 . Olive and Toole $^{15}$ found that their "image shift" thresholds were approximately $7 \mathrm{~dB}$ higher than the timbral thresholds. According to the discussion in Sec. IV A it was, however, expected that the "image shift"' threshold would be some where between the timbre thresholds and the threshold based on the present "separate sound source", definition. It should, however, be remembered that it was not possible to detect any changes in the simulated sound field corresponding to the Olive and Toole ${ }^{15}$ definition. Thus care should be taken when relating the threshold values based on the two definitions.

It should be noted that the TD's for spatial aspect and timbre are only significantly different for reflections 1,5 and 9 and that the $95 \%$ confidence interval of the timbre threshold is nearly twice the value of the interval for the spatial threshold. This suggests that the psychometric functions for spatial aspects are apparently steeper than those for timbre.

The results thus indicate that subjects are able to reliably discriminate between the two types of changes in the auditory impression.

The use of loudness differences as cues were also examined. Papers I and II reported on measurements of SPL differences between the standard and the comparison stimulus with the reflection at TD values similar or higher than those reported in this paper. As all the SPL differences corresponding to those TD's were lower than those required for discrimination based on loudness differences, it is concluded that loudness could not have been a cue in any of the present situations.

\section{Comparison of natural levels and measured thresholds of individual reflections}

The TD's for spatial aspects are shown in Fig. 3 for the noise signal, together with the natural levels. The TD's for reflections 1 (floor), 5 (ceiling), and 9 (left wall) are either

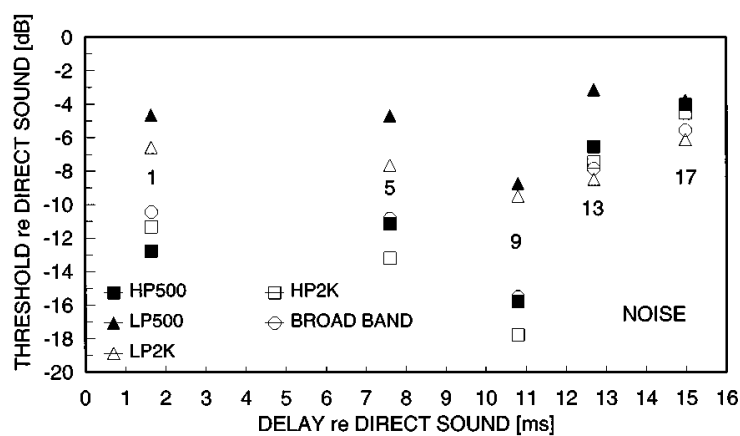

FIG. 4. Mean threshold values for a change in spatial aspects for the unfiltered situation as a function of band width of the noise signal. The mean values are based on three subjects and four repetitions for each subject. Confidence intervals $(95 \%)$ based on the within-subject variance are $\pm 1.2 \mathrm{~dB}$ (broadband), $\pm 1.1 \mathrm{~dB}($ LP500 Hz), $\pm 1.8 \mathrm{~dB}($ HP500), $\pm 1.1 \mathrm{~dB}$ $(\mathrm{LP} 2 \mathrm{~K})$ and $\pm 1.8 \mathrm{~dB}(\mathrm{HP} 2 \mathrm{~K})$. The individual reflection numbers are shown according to Table I.

lower or not significantly different from the natural levels. This suggests that the first order reflection from the floor and second order reflections from the ceiling and left-hand wall contribute on an individual basis to the auditory spatial aspects of the sound field.

The TD's for timbre for reflections 1, 5, and 9 are all seen to be significantly lower than the natural levels and thereby contributing individually to the timbre of the sound field. This confirms the findings of Paper II for reflections 1 and 9, although the present TD's are lower than those found in Paper II. The discussion in Sec. VI C shows that the differences in the TD's are the result of using two different experimental procedures.

The results of Papers I and II, and the present thus indicate that the first order reflection from the floor and the second order reflections from the left hand wall will individually influence both timbral and spatial aspects of the sound field.

\section{Threshold of detection for individual reflections for high- and low-pass filtered noise signals}

The frequency bandwidth of the signal is known to have an influence on the ability to localize a sound source (see Blauert $^{21}$ for a review). Further, it would be of great interest for the designers of loudspeakers to know how the different frequency ranges influence the spatial aspects, as this would help in the definition of how loudspeaker directivity characteristics should be designed as a function of frequency.

Thus, it was decided to conduct a series of experiments with the purpose of examining the influence of frequency range of the signal. Threshold values were measured using high- and low-pass filtered pink noise. The crossover points for the high- and low-pass filters were chosen to be representative of the crossover frequencies used in standard two or three-way loudspeaker systems.

The TD's for high- and low-pass filtered noise signals are shown in Fig. 4, together with the TD's for a broadband noise signal from Fig. 3. The results show that the TD's increase significantly for reflections $1,5,9$, and 13 when the signal is low-pass filtered at $500 \mathrm{~Hz}$ and for reflections 1,5 , and 9 when the signal is low-pass filtered at $2 \mathrm{kHz}$. The threshold values for the high-pass filtered signal are not sig- 
nificantly different from the broadband based thresholds. Here, it is interesting to note that the results reported in paper II suggested that the spectral changes in the frequency range $500 \mathrm{~Hz}-2 \mathrm{kHz}$ are most important for the threshold detection of timbral differences.

A comparison between the natural levels (see Fig. 3) and the TD's shown in Fig. 4 shows that the TD's for both highand low-pass filtered signals for reflection 1 are lower than the natural levels. For reflections 5 and 9 only the high-pass filtered TD's are lower than the natural levels. For reflections 13 and 17 all the filtered TD's are higher than the naturals levels.

The results thus suggest that the spectral energy above 2 $\mathrm{kHz}$, for some of the individual reflections, determines the degree of influence the reflection will have on the spatial aspects of the reproduced sound. The results show that reflections 1 (floor), 5 (ceiling), and 9 (left wall) are so strong that they will contribute separately to the spatial aspects, if their spectra contain sufficient energy in the frequency range above $2 \mathrm{kHz}$. If the reflections only contain energy below $500 \mathrm{~Hz}$, only the first-order floor reflection will contribute to spatial aspects.

\section{B. Results for the filtered situation}

The purpose of these experiments (nos. 7 and 8 in Table IV) was to measure the threshold of detection for individual reflections, with transfer functions modified according to measured directivity characteristics of a real loudspeaker, and absorption as a function of frequency for the room surfaces. The measured thresholds will be compared with those for the unfiltered situation to assess the effect of the filtering, and also compared with the "natural" level of the reflection as calculated by an image model. Note that the use of the natural levels is a compromise to describe the transfer functions shown in Fig. 1 by a single number. It is seen to be a reasonable approximation for reflections 1,13 , and 17. The threshold values for the filtered situation are assumed to be more in accordance with the conditions of a real room. The thresholds have also been measured using speech in order to assess the importance of signal type.

\section{The influence of filtering}

The measured threshold values for the filtered situation are compared to those of the unfiltered situation and the natural levels, in Fig. 5.

The thresholds for the filtered situation are significantly higher for all reflections except reflection 17, and especially large changes are seen for reflections 5 and 9. A visual inspection of the transfer functions for the individual reflections shown in Fig. 1 shows that the filtering mainly attenuates energy in the middle and high frequency regions. This is especially the case for reflections 5 and 9 . These two reflections also have the largest changes in their TD's. The changes in threshold level caused by the introduced filtering are thus in agreement with the results based on the high- and low-pass filtered signals, shown in Fig. 4.

The effect of the filtering is also that all thresholds except that for reflection 1 are now significantly above the natural levels. This means that only the first-order floor re-

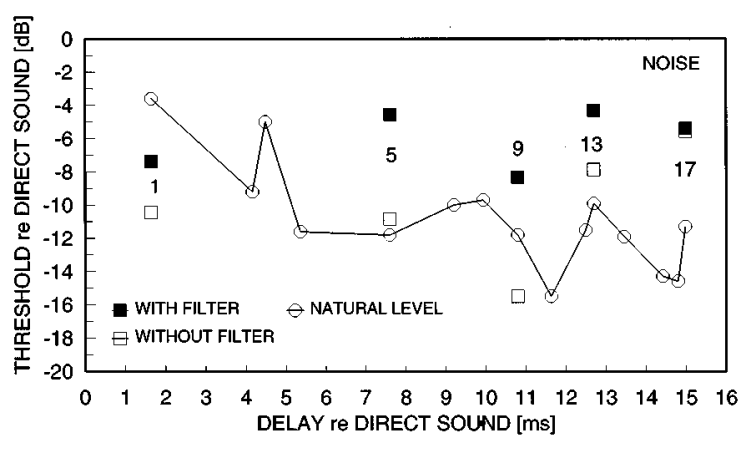

FIG. 5. Mean threshold values for a change in spatial aspects for the filtered and unfiltered situations for the noise signal. The mean values are based on three subjects and four repetitions for each subject. Confidence intervals $(95 \%)$ based on the within-subject variance are $\pm 1.1 \mathrm{~dB}$ (filtered) and $\pm 1.2 \mathrm{~dB}$ (unfiltered). The natural levels of the individual reflections based on an image model are also shown as are the individual reflection numbers according to Table I.

flection is likely to be individually audible and so be able to influence the spatial aspects of the sound field.

\section{The influence of signal type}

Previous results (Olive and Toole, ${ }^{15}$ Papers I and II) have shown that the signal type can have an influence on TD values for timbre so it was decided to test this for the spatial aspects as well. Two classes were identified: continuous and discontinuous sounds represented in this experiments by noise and speech, respectively.

The thresholds of detection for the noise and speech signals are shown in Fig. 6. The threshold values for the speech signal are seen to be significantly higher than those for the noise signal for all reflections. This has the consequence that the thresholds for the speech signal are all higher than the natural levels (see Fig. 5) except for reflection 1. This suggests that only reflection 1 will individually influence the spatial aspects for signals like speech.

A comparison between threshold values based on noise, low-pass filtered at $500 \mathrm{~Hz}$ and the speech signal, respectively shows that the thresholds are not significantly different except for reflections 5 and 9 . The similarity between the

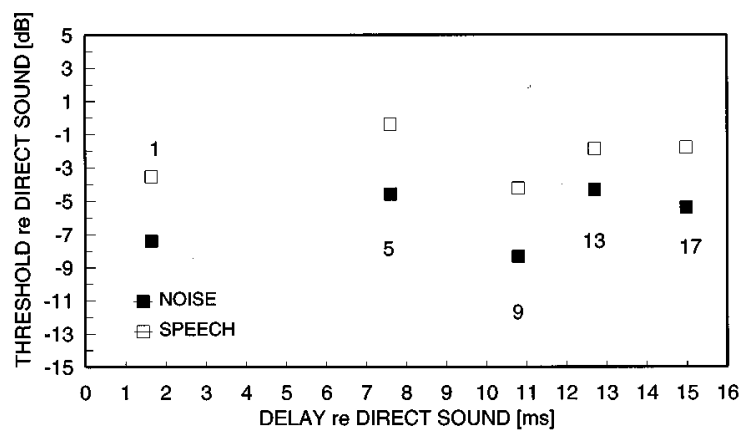

FIG. 6. Mean threshold values for a change in spatial aspects for the filtered situation and speech and noise. The mean values are based on three subjects and four repetitions for each subject. Confidence intervals $(95 \%)$ based on the within-subject variance are $\pm 1.1 \mathrm{~dB}$ (noise) and $\pm 0.8 \mathrm{~dB}$ (speech). The individual reflection numbers are shown according to Table I. 


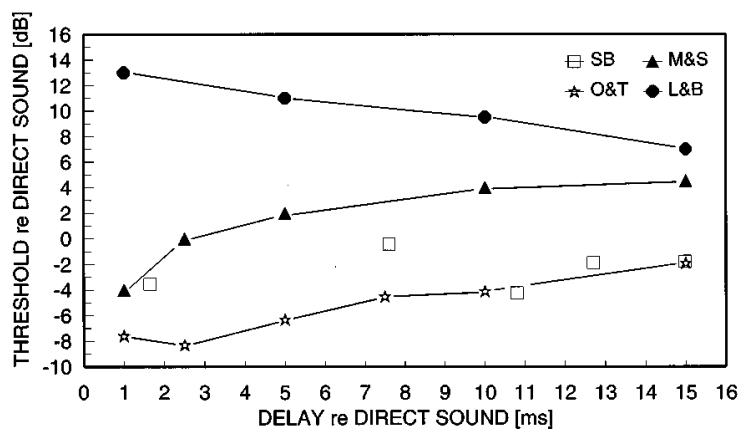

FIG. 7. Results from Meyer and Schodder ${ }^{13}$ (M\&S) (anechoic), Lochner and Burger ${ }^{14}$ (L\&B) (anechoic), Olive and Toole ${ }^{15}$ (O\&T) (IEC room), and the TD's from Fig. 6 (SB) plotted for comparative reasons. The signal was speech for all cases and the note in brackets indicate in which environment the data were obtained.

thresholds could be explained by the fact that the spectrum of the speech signal has its main part of the energy in the frequency range $70-500 \mathrm{~Hz}$.

\section{DISCUSSION}

\section{A. Comparison with the literature}

This investigation is, to the knowledge of the author, the first to measure the threshold of detection of several individual reflections for a change in the spatial aspects of a reproduced sound field. No other results are therefore available to directly compare with, however, a number of results have been published for situations that are closely related so these will be examined in the following.

Olive and Toole ${ }^{15}$ measured the "image shift" threshold for a single controlled reflection using speech in an anechoic chamber, a semianechoic room and a standard listening room. Their "image shift" threshold criterion was, as discussed in Sec. IV A, however, different from the present. Meyer and Schodder ${ }^{13}$ and Lochner and Burger ${ }^{14}$ measured the threshold for a single reflection in an anechoic chamber using speech for a number of threshold definitions including one similar to the present. For comparisons, the results of Olive and Toole, ${ }^{15}$ Meyer and Schodder, ${ }^{13}$ Lochner and Burger, ${ }^{14}$ and the TD's for speech from Fig. 6 are shown in Fig. 7.

The difference between the Meyer and Schodder ${ }^{13}$ and Lochner and Burger's ${ }^{14}$ results are at least partly due to the difference between the threshold definition "echo barely inaudible" as defined by Meyer and Schodder ${ }^{13}$ and "echo clearly audible" as used by Lochner and Burger. ${ }^{14}$ The present TD's are based on a threshold definition that is most similar to that used by Lochner and Burger ${ }^{14}$ so the difference between their results and the present suggest that the presence of other individual reflections and a reverberant field increases the audibility of individual reflection quite significantly. This would be supported by results of Leakey and Cherry ${ }^{22}$ and Chiang and Freyman ${ }^{23}$ who showed that addition of noise uncorrelated both spatially and electrically with the main signal increased the audibility of a delayed signal significantly. Cremer and Müller ${ }^{4}$ has shown that the reverberant field is uncorrelated with the individual reflec- tions and it is argued in Paper I that this also applies to the simulated sound field.

Olive and Toole' ${ }^{15}$ results, obtained in a listening room similar to the present, are shown in Fig. 7. They are seen to be significantly lower than the present TD's for short delay times $(<10 \mathrm{~ms})$ and similar for longer delays. The lower thresholds could be explained by the difference between the "image shift" and "separate sound source" definitions as discussed in Sec. IV A. However, as discussed in Sec. V A 1, it might not be possible to compare the two situations as the Olive and Toole ${ }^{15}$ defined threshold did not exist in the simulated sound field.

The hypothesis that the reverberant field increases the audibility of individual reflections is not completely supported by the results of Olive and Toole. ${ }^{15}$ They found insignificant differences between threshold values for short delays $(<8 \mathrm{~ms})$ in the three tested environments. For longer delays $(10-20 \mathrm{~ms}$ ) they found larger differences (up to $6 \mathrm{~dB}$ ), but only partly supporting the hypothesis. Two factors should be considered in this context. The first is that the loudspeaker used to simulate the investigated reflection, had the same full bandwidth as the loudspeaker producing the direct sound. This means that there must have been a spectral difference between the natural reflection, present when the test reflection was switched off, and the test reflection. Freyman et al. ${ }^{24}$ and Clifton et al. ${ }^{25}$ have shown that sudden changes in the spectral content of the reflection causes the precedence effect to break down. The second factor is the "plausibility effect" suggested by Rakerd and Hartmann. ${ }^{26}$ They showed that if the delay, the spectrum or the angle of incidence of the reflection are not "plausible" in relation to the test environment it will cause the precedence effect to break down. Both of these factors could have had an influence on the thresholds obtained by Olive and Toole.

\section{B. Comparison with results on the precedence effect}

The precedence effect is the effect that the auditory event appears in a single direction determined by the direction of the first arriving wavefront. Later arriving wavefronts, for example reflections from walls close to the sound source emitting the first wavefront, does not influence the directional impression.

Experiments on this phenomena requires a definition of the threshold and as the discussion in Sec. IV A indicated, several definition have been used by the researchers in this field. The reader is referred to Blauert ${ }^{21}$ (sections 3.1.2, 4.4.2, and 5.4) for further discussions of threshold definitions.

The definition used by Blauert ${ }^{21}$ is the so-called "echo" threshold where "echo" refers to the impression of a second auditory event in addition to the primary event generated by the first wave front. Note that "echo" includes more than the traditional definition of an echo, that is a replication of an auditory event, separated in time from the first. Blauerts "echo" threshold definition is that introduced by Lochner and Burger ${ }^{14}$ where the "echo is clearly audible." This definition is quite close to the definition used by the author for the present series of experiments as the subjects were instructed to stop the experiment when they could just dis- 
criminate between the standard and the comparison stimulus. It was therefore found worthwhile to compare the obtained results to some of those reported in the literature on the precedence effect. Blauert ${ }^{21}$ has an excellent review of the results on the precedence effect, so only results in direct relation to the present investigation will be examined.

\section{The effect of angle of incidence of the reflection}

Rakerd and Hartmann ${ }^{26}$ found that vertical reflections have a smaller influence on the precedence effect compared to horizontal reflections. This applies to delay times in the range 0.6 to $2.3 \mathrm{~ms}$. However, Guski ${ }^{27}$ found that adding reflective surfaces on the floor and ceiling in an otherwise anechoic environment had a larger influence on localization accuracy compared to adding surfaces in the horizontal plane (walls). The reported results are in agreements with the results of Guski, ${ }^{27}$ as only the floor reflection is likely to have a significant influence on the spatial aspects of the sound field.

\section{The effect of signal bandwidth}

The influence of signal bandwidth on the effectiveness of the precedence effect has been examined by Blauert and Cobben ${ }^{28}$ using a standard stereophonic arrangement and narrow-band (one-third octave) pulses with center frequencies $0.5,1$, and $2 \mathrm{kHz}$. They found that the horizontal angle of the sound image as a function of delay of the right loudspeaker signal was similar for the broadband signal and the 2 $\mathrm{kHz}$ signal. The mean values for the 1 and $0.5 \mathrm{kHz}$ signals deviated from the broadband results, and varied strongly as a function of the delay of the signal. This leads to the conclusion that the precedence effect shows anomalies for low frequency narrow-band signals. The results in Fig. 4 also suggest that the localization mechanism works differently for high- and low-pass filtered signals. The broadband noise thresholds are similar to those for the 0.5 and $2 \mathrm{kHz}$ highpass filtered noise, and significantly different from those based on low-pass filtered noise at 0.5 and $2 \mathrm{kHz}$. These results are further supported by Blauert and $\mathrm{Col}^{29}$ who found that the echo thresholds in a precedence effect paradigm were similar for broadband impulses, $2.5 \mathrm{kHz}$ bandpass, and 2.7-3.4 kHz bandpass impulses. Low-pass filtered impulses at $1 \mathrm{kHz}, 1.5 \mathrm{kHz}$, and $270 \mathrm{~Hz}-340 \mathrm{~Hz}$ bandpass filtered impulses had significantly higher echo threshold values. Freyman et $_{\text {al. }}{ }^{24}$ also found evidence that the echo suppression is influenced differently for high- and low-pass filtered signals.

Blauert and Cobben ${ }^{28}$ attributed the anomalies in the precedence effect at lower frequencies to the fluctuation in position of the absolute maximum of the interaural cross correlation function (IACCF). They speculate that the position of the maximum corresponding to the first sound will fluctuate for several milliseconds and this will interact with the maximum corresponding to the delayed sound. If this assumption is correct it follows that (1) the precedence effect should return to normal for delays longer than the time of fluctuation and (2) that the use of a stationary signal would enable the subject to delay the decision on the position of the sound source until the IACCF had stabilized. This suggests that the anomalies observed at low frequencies using click stimuli would not be present if a continuous signal was used. However, the results in Fig. 4 shows that the TD's also depends on the frequency content for a stationary signal, for reflections with delays similar to the length (1-2 ms) of the fluctuations in the IACCF, and for reflections with delays so long that the IACCF should have stabilized. This suggests that the difference in threshold values for the high- and lowpass filtered signal, as shown in Fig. 4, cannot be explained by fluctuations in the IACCF for the low-pass filtered signals.

Another factor should be considered for an explanation of the dependency of frequency range for the precedence effect. This is a subject's ability to localize low-pass filtered signals. Hartmann ${ }^{30}$ noted that it is very difficult to localize low frequency pure tones in a room. He noted that subjects in that case adopt a strategy with a high consistency, but that the strategy depends strongly on the subject. The same tendency has been observed in the present experiments. The between-subject variance was four to ten times higher for the low-pass filtered signals compared to the broadband and high-pass filtered signals. However, the within-subject variance (consistency) was similar for all the signal types. Subjects also reported that they had difficulty in finding a cue for the low-pass filtered signals.

\section{Influence of experimental procedure}

The method of adjustment (MOA) has been used for the experiments reported in this paper for reasons discussed in Sec. IV C. However, the results presented in Papers I and II on the detection of timbral differences are based on an adaptive two alternative forced choice ( $2 \mathrm{AFC}$ ) procedure, and in order to be able to compare the two sets of results, the threshold of detection for timbre is shown for the two procedures in Fig. 8. The thresholds of detection, based on the MOA procedure, are seen to between 3-5 dB lower than those based on the 2 AFC procedure. This range of differences is in agreement with that observed by $\mathrm{Bech}^{31}$ for experiments on a single reflection in combination with the direct sound.

\section{SUMMARY OF FINDINGS}

This section contains a summary of the major findings. The validity and generality of these depend among other things on the accuracy of the electroacoustic simulation of the sound field. This subject has been discussed in some detail in Papers I and II and readers are referred to those papers. The validity of the findings also depends on the generality of the characteristics of the modeled loudspeaker and the room.

The loudspeaker was a standard two-way system both in terms of size, electrical, and acoustic characteristics. It is still believed to be representative of a large portion of today's available loudspeaker systems.

The dimensions of the modeled room and its reverberation time are within the requirements of the IEC 268-13 recommendation, whereby the room should be representative of a domestic listening room. The modeled absorption charac- 


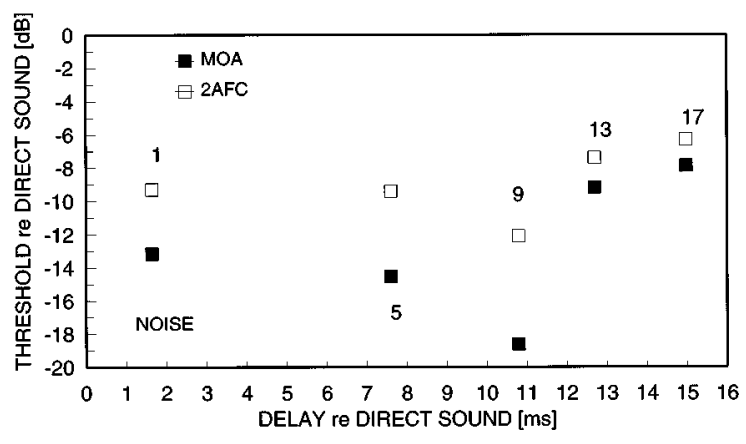

FIG. 8. Mean threshold values for a change in timbre for the unfiltered situation and the noise signal obtained by Method of Adjustment (MOA) and an adaptive (two down-one up) two-alternative forced choice procedure (2AFC). Mean values are based on three subjects and four repetitions per subject (MOA) and eight subjects and 400 trials per subject (2AFC). Confidence intervals $(95 \%)$ based on the within-subjects variance are $\pm 1.2 \mathrm{~dB}$ (MOA) and $\pm 1 \mathrm{~dB}$ (2AFC). The individual reflection numbers are shown according to Table I.

teristics are based on the actual materials used in the room. The carpet is typical of a Danish domestic carpet used in living rooms, etc., and it is difficult to estimate how representative this would on a world wide basis. The absorption characteristics of the walls are determined by a specially constructed panel system that includes both membrane (lowfrequency) and porous (high-frequency) absorbers. The same panel was used on all walls so the same absorption characteristics could be used for all walls. This would not be seen as representative of a standard domestic room and the same apply for the use of membrane absorbers on the walls. The ceiling consists of a flat and highly reflective metal surface that functions as a cooling panel. The absorption characteristics are only slightly higher than those of a painted hard surface like concrete. Such surfaces are fairly common in Denmark and are also believed to be representative of many modern buildings in Europe.

The results have indicated that the spectral energy above $2 \mathrm{kHz}$ of the individual reflection determines the importance of the reflection for the spatial aspects. The discussion above thus indicates, that the influence of the wall reflections would be underestimated in the modeled situation, because of the nontypical porous absorbers on the wall surfaces. The influence of the floor reflection would tend to be overestimated, especially in rooms where a carpet with more high frequency absorption was used. However, although such carpets are fairly common in certain countries, they are not in the northern part of Europe. Thus to conclude on the generality of the results: they are strictly speaking only applicable to rooms that are acoustically fairly similar to that modeled.

It should also be emphasized that the findings of this paper are based on the threshold of detection values. This means that one should be careful when discussing the qualitative effects of reflections that have levels above the measured threshold values. This is especially important if the results are used as basis for, for example, the design of the directivity characteristics of loudspeaker systems.

The major findings are:
(1) Subjects can reliably discriminate between spatial and timbre cues.

(2) The spectral energy above $2 \mathrm{kHz}$ of individual reflections determines the degree of influence the reflection will have on the spatial aspects of the reproduced sound field.

(3) Under conditions as in the simulated room, with a standard two-way loudspeaker system reproducing broadband noise or speech, only the first order floor reflection is so strong that it will contribute separately to the spatial aspects of the sound field.

\section{ACKNOWLEDGMENTS}

This work was financed by the Danish Research Council. The guidance of S. K. Pramanik and P. Chapman in use of the English language is gratefully acknowledged. The author would also like to thank the reviewers for very helpful comments.

${ }^{1}$ S. Bech, "Timbral aspects of reproduced sound in small rooms. I," J. Acoust. Soc. Am. 97, 1717-1726 (1995).

${ }^{2}$ S. Bech, "Timbral aspects of reproduced sound in small rooms. II," J. Acoust. Soc. Am. 99, 3539-3549 (1996).

${ }^{3}$ IEC Recommendation 268-13. "Sound System Equipment, Part 13: Listening Tests on Loudspeakers." International Electrotechnical Commission, Publication 268-13, 1985.

${ }^{4}$ L. Cremer and H. A. Müller (translated by T. J. Schultz), Principles and Applications of Room Acoustics (Applied Science Publishers, New York, 1982), Vol. 1, pp. 17-19.

${ }^{5}$ J. M. Berman, "Behaviour of sound in a bounded space," J. Acoust. Soc. Am. 57, 1275-1291 (1975).

${ }^{6}$ J. H. Rindel, "Modeling the angle-dependent pressure reflection factor," Appl. Acoust. 38, 223-234 (1993).

${ }^{7}$ Note that Rindel ${ }^{6}$ concludes that the diffuse field coefficient should be set equal to the absorption at 55 degrees angle of incidence. The 55 degrees was found in experiments conducted after the present. The maximum error is $0.9 \mathrm{~dB}$ for 100 and $125 \mathrm{~Hz}$ for reflection No. 5. For all other situations the error is smaller than $0.5 \mathrm{~dB}$.

${ }^{8}$ L. R. Fincham and R. H. Small, "The application of digital signal processing to large scale simulation of room acoustics. Part I-Signal processing requirements in the Archimedes project," 90th Convention of The Audio Engineering Society, Paris, France, 19-22 February (1991), Preprint 3055 .

${ }^{9}$ D. M. Brookes, R. I. Harris, and R. J. Wilson, “The application of digital signal processing to large scale simulation of room acoustics. Part III-DSP engine hardware topology and control software for multichannel simulation," 90th Convention of The Audio Engineering Society, Paris, France, 19-22 February (1991), Preprint 3057.

${ }^{10} \mathrm{~K}$. B. Christensen, "The application of digital signal processing to large scale simulation of room acoustics. Part II-Frequency response modeling and optimization software for a multichannel DSP engine,'” J. Audio Eng. Soc. 40, 260-276 (1992).

${ }^{11}$ V. Hansen and G. Munch, "Making recordings for simulation tests in the Archimedes Project," J. Audio Eng. Soc. 39, 768-774 (1991).

${ }^{12}$ H. Haas, "Über den Einfluss eines Einfachechos auf die Hörsamkeit von Sprache," Acustica 1, 49-58 (1951) ["The influence of a single echo on the audibility of speech," J. Audio Eng. Soc. 20, 147-159 (1972)].

${ }^{13}$ E. Meyer and G. R. Schodder, "Über den Einfluss von Schallrückwürfen auf Richtungslokalisation und Lautstärke bei Sprache," Nach. Akad. Wiss. Göttingen, Math. Phys., Klasse IIa 6, 31-42 (1952).

${ }^{14}$ J. P. A. Lochner and J. F. Burger, "The subjective masking of short time delayed echoes by their primary sounds and their contribution to the intelligibility of speech," Acustica 8, 1-10 (1958).

${ }^{15}$ S. E. Olive and F. E. Toole, "The detection of reflections in typical rooms," J. Audio Eng. Soc. 37, 539-553 (1989).

${ }^{16} \mathrm{~F}$. E. Toole, "Loudspeakers and rooms for sterephonic sound reproduction," Proceedings of 8th International Conference of the Audio Engineering Society, 3-6 May, Washington, DC, 71-91 (1990). 
${ }^{17}$ H. P. Seraphim, "Über die Wahrnehmbarkeit mehrerer Rückwürfe von Sprachschall," Acustica 11, 80-91 (1961).

${ }^{18}$ B. L. Cardozo, "Adjusting the method of adjustment: SD vs DL," J. Acoust. Soc. Am. 37, 786-792 (1965).

${ }^{19}$ C. C. Wier, W. Jesteadt, and D. M. Green, "A comparison of method-ofadjustment and forced-choice procedures in frequency discrimination," Percept. Psychophys. 19, 75-79 (1976).

${ }^{20}$ A. Hesse, "Comparison of several psychophysical procedures with respect to threshold estimates, reproducibility and efficiency," Acustica 59, 263-273 (1986).

${ }^{21}$ J. Blauert, Spatial Hearing. The Psychophysics of Human Sound Localization (MIT, London, 1997).

${ }^{22}$ D. M. Leakey and E. C. Cherry, "Influence of noise upon the equivalence of intensity differences and small time delays in two loudspeaker systems," J. Acoust. Soc. Am. 29, 284-286 (1957).

${ }^{23}$ Y. Chiang and R. L. Freyman, "The effect of background noise on the precedence effect,"' J. Acoust. Soc. Am. 97, 3280 (A) (1995).

${ }^{24}$ R. L. Freyman, R. K. Clifton, and D. D. McCall, "Sudden changes in simulated room acoustics influence echo suppression," J. Acoust. Soc. Am. 95, 2898 (A) (1994).

${ }^{25}$ R. K. Clifton, R. L. Freyman, R. Y. Litocski, and D. D. McCall, "Listeners' expectations about echoes can raise and lower echo threshold," J. Acoust. Soc. Am. 95, 1525-1533 (1994).

${ }^{26}$ B. Rakerd and W. M. Hartmann, "Localization of sound in rooms. II: The effects of a single reflecting surface," J. Acoust. Soc. Am. 78, 524-533 (1985).

${ }^{27}$ R. Guski, “Auditory localization: effects of reflecting surfaces," Perception 19, 819-830 (1990).

${ }^{28}$ J. Blauert and W. Cobben, "Some consideration of binaural cross correlation analysis," Acustica 39, 96-104 (1978).

${ }^{29}$ J. Blauert and J. Col, "Irregularities in the precedence effect," Adv. Biosci. 83, 531-539 (1992).

${ }^{30}$ W. M. Hartmann, "Localization of sound in rooms," J. Acoust. Soc. Am. 74, 1380-1391 (1983).

${ }^{31}$ S. Bech, "Audibility of a single reflection with short delay times," 13th International Congress on Acoustics, Yugoslavia 1, 447-450 (1989). 